\title{
Spinal cord injuries in South African Rugby Union (1980 - 2007)
}

\author{
Fiona J Hermanus, Catherine E Draper, Timothy D Noakes
}

Objectives and design. To address an apparent increase in the number of rugby-related spinal cord injuries (SCIs) in South Africa, a retrospective case-series study was conducted on injuries that occurred between 1980 and 2007. We aimed to identify preventable causes to reduce the overall rate of SCIs in South African rugby.

Methods. We identified 264 rugby-related SCIs. A structured questionnaire was used, and it was possible to obtain information on a total of 183 players, including 30 who had died.

Results. SCIs increased in number in the 1980s and in 2006 Forwards sustained $76 \%$ of all SCIs, and club players $60 \%$. Players aged 17 had the highest number of SCIs. In only $50 \%$ of cases were medical personnel present at the time of injury, and $49 \%$ of injured players waited longer than 6 hours for acute management. Of players with an SCI, $61 \%$ had a catastrophic outcome after 12 months, including $8 \%$ who died during that time; $65 \%$ received no financial compensation; and only $29 \%$ of players had medical aid or health insurance. Conclusion. A register of all rugby-related SCIs in South Africa is essential to monitor the magnitude of the problem, identify potential risk factors, and formulate appropriate preventive interventions. The lack of reliable denominator data limits calculation of incident rates. Players from previously disadvantaged communities in particular suffered the consequences of limited public health care resources and no financial compensation.

S Afr Med J 2010; 100: 230-234.
Concerns about spinal cord injuries (SCIs) in South African rugby players were first raised in $1977,{ }^{1}$ concurrent with similar concerns in other countries. ${ }^{2-4}$ Since then, at least 50 publications on spinal cord injuries in rugby have established that, despite their relative infrequency in terms of player exposure, these injuries are a major cause of serious morbidity and mortality in rugby ${ }^{5,6}$ Of all organised sports in South Africa (SA), rugby has the highest incidence of SCI.

Accurate determination of the number of SCIs occurring in rugby and the risks faced by players has been hampered by the relative rarity of these injuries and a lack of standardised procedures for data collection. ${ }^{6}$ Despite calls for properly controlled studies and centralised registers for spinal injuries since the $1970 \mathrm{~s},{ }^{6,7}$ progress has been limited. ${ }^{6}$ Lack of reliable 'denominator' data, i.e. the total number and playing exposure of rugby players, has been a further impediment. ${ }^{8}$ Without reliable information, understanding how, when and why injuries occur, and a standard injury definition, it is not possible to formulate effective management strategies to reduce injury risk.

New Zealand has relatively accurate data, as referees and teams must report any rugby-related cervical or head injuries requiring hospitalisation. Using those data, it was shown that the adoption of a specific intervention programme,

School of Public Health and Family Medicine, University of Cape Town Fiona J Hermanus, BSc (Physiotherapy), MPH

UCT/MRC Research Unit for Exercise Science and Sports Medicine, University of Cape Town

Catherine E Draper, MA, PhD

Timothy D Noakes, MB ChB, MD, DSc, FACSM (Hon), FFSEM (UK)
RugbySmart, reduced the incidence of scrum-related SCIs in New Zealand rugby after 2001. ${ }^{8}$ Noakes and Draper ${ }^{9}$ concluded that strong government support and advocacy by rugby administrators are required to reduce the incidence of these injuries, but suggested that countries like SA and Fiji, with limited resources for quality training, coaching and medical services, face great challenges in achieving this objective. Ultimately, the responsibility of establishing national and international SCI registers lies with Rugby Union (RU) authorities.

After an apparent reduction in the number of rugby-related SCIs in the Western Cape, an increase was noted in 2006 by SA rugby administrators, ${ }^{10}$ the SA rugby community and the Chris Burger/Petro Jackson Players' Fund (CBPF). Nineteen catastrophic injuries with 3 deaths were reported in the first 7 months of the 2006 SA rugby season. To address these alarming statistics, the SA RU hosted a Rugby Safety Indaba in August 2006. A key area identified was the need to develop methods to collect accurate data on rugby-related SCIs throughout SA, not just in one province, as in previous SA studies. ${ }^{10-12}$

This study, commissioned by the Indaba, describes the first set of retrospective data on all rugby-related SCIs in SA since 1980. The aim was to identify preventable causes to reduce the overall rate of rugby-related SCIs and the rate of those leading to catastrophic injuries. Accordingly, the study objectives were to: (i) establish an inventory of rugby-related SCIs that occurred in SA rugby from 1980 to July 2007; and (ii) use this inventory to describe the nature of these injuries, demographics of injured players, the distribution of injuries in $\mathrm{SA}$, and treatment received by injured players.

\section{Methods}

For this retrospective case-series study, an SCI questionnaire was developed through a consultative process with relevant stakeholders. Questions covered player demographics, 
training, phase and stage of play during injury, playing position, weather and ground conditions, type and level of injury, medical management immediately after injury and in hospital, and immediate and final outcomes of injury. SCIs leading to death (at the time or subsequent to the injury), quadriplegia or dependency on a wheelchair were classified as catastrophic injuries. Interviews were conducted telephonically, in person, by e-mail, by post or online from January 2007 to July 2007. Information was captured using PocketSurvey, a secure web-based data-collecting system that protected the player's identity. Data were analysed using Intercooled Stata Version 8.2 (StataCorp, Texas, USA).

The dataset was incomplete owing to poor recall of some information, which accounts for the variance in the denominators $(N)$ for the results presented in the sections that follow. To improve accuracy of injury information supplied by the players, medical reports were requested from health facilities and clinicians who managed the players. The player's consent for participation in this study was provided to the health facility and/or clinician. Some facilities had destroyed the player's medical records as per SA regulations for preservation of medico-legal documentation, some requested payment for records, and some requests were ignored.

Ethical approval for the study was granted by the University of Cape Town's Research Ethics Committee (REF REC $390 / 2006)$

\section{Results and discussion}

\section{Total number of SCIs}

A total of 264 rugby-related SCIs were identified since 1980, all in males. Of the players, 67 had died, 26 could not be traced and $18 \mathrm{did}$ not respond. One hundred and nineteen players gave written consent for participation and for access to their medical records; 3 subsequently could not be traced. Of the 264 players, information on a total of 183 was gathered, including 30 deceased players. Information on 37 of the 183 players was obtained through the CBPF. It is not possible to infer how the missing information on the remaining 81 players (44 met inclusion criteria and 37 had died) would have influenced the results of the study, but there is no reason to believe that those players or their injuries would differ from the players and the injuries in this study.

\section{Annual number of SCIs}

Fig. 1 shows the annual number of SCIs between 1980 and July 2007 traced by this study $(N=180)$. These data represent a true minimum number of such cases. Data collected in other studies on rugby spinal cord injuries in $\mathrm{SA}^{10-12}$ covering the period 1963 - 1997 add 100 SCIs (Fig. 1). Note that the present data were collected nationally for SA, whereas other studies ${ }^{10-12}$ only reported on injuries treated in one hospital in the Western Cape.

There are grounds for concern about the high number of SCIs noted for the first time in 1977. ${ }^{1}$ The number appeared to have increased in the 1980s, ${ }^{12-13}$ and again in 2000 and 2006 (Fig. 1, arrowed). In the absence of denominator data we cannot be certain that this represents a true increase in the

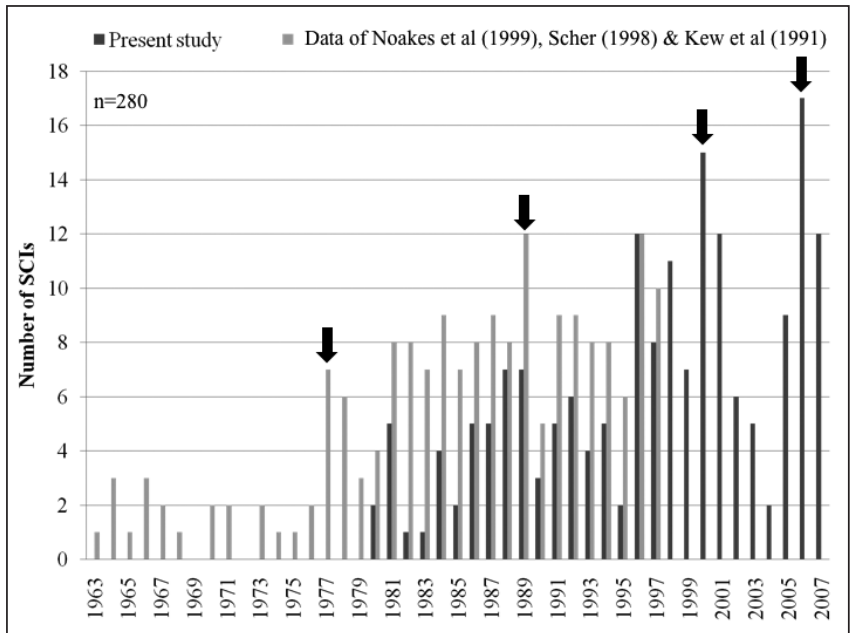

Fig. 1. Annual number of SCIs in SA, including additional data. ${ }^{10-12}$

rate of injury. However, it is unlikely that the number of rugby players in SA could have increased proportionate to the increase in the number of SCIs in the same period.

Compared with the annual number of catastrophic SCIs in Australia and New Zealand relative to the numbers of registered players in these countries as documented by the International Rugby Board, SA generally has fewer SCIs per year (Fig. 2). In the absence of contradictory information it is assumed that the number of registered players has not fallen dramatically during the same period.

\section{Number of SCIs by provincial unions}

Twenty per cent of injuries $(N=133)$ occurred in the Boland and 20\% in the Western Provincial (WP) RUs, followed by the Border and Eastern Provincial (EP) RUs with 11\% each. Denominator data per province are not available, either as player hours or number of players per province. However, provincial match data were available for 12 of the 14 provincial unions in 2006 (Table I). The data show a 10-fold variation in the number of matches per SCI and hence a 10-fold variation in $\mathrm{SCI}$ risk for the eight provinces that reported one or more SCIs in the 2006 rugby season. Although the number of matches (not absolute) was only known for 2006 in 12 provincial unions, we believe that this would not have differed significantly for the period from 1980 to 2007.

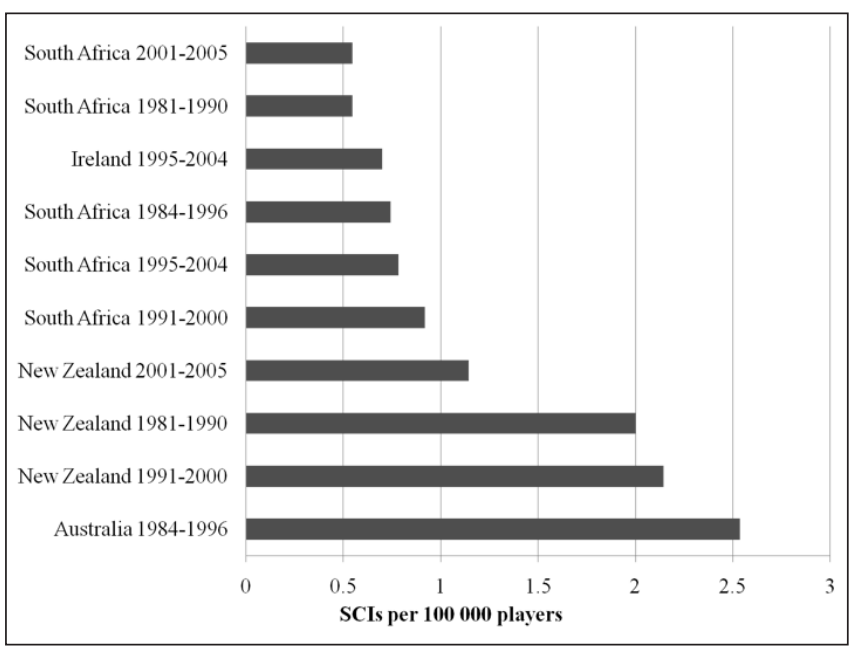

Fig. 2. SCIs per 100000 players in SA and other countries. 
Table I. Number of matches and number of injuries by province in 2006

\begin{tabular}{llll}
\hline Provincial Union & Matches & SCIs & Matches per SCI \\
\hline Blue Bulls (Gauteng - North) & 5400 & 2 & 2700 \\
Border & 2961 & 2 & 2961 \\
Free State & 6125 & 3 & 3063 \\
South Western Districts & 9325 & 1 & 6825 \\
Leopards (Gauteng - West) & 6825 & 3 & 13783 \\
Boland & 41350 & 1 & 14900 \\
Valke (Gauteng - East) & 14900 & 1 & 20025 \\
Western Cape & 20025 & 0 & - \\
KwaZulu-Natal & 18400 & 0 & - \\
Golden Lions (Gauteng - Johannesburg) & 8000 & 0 & - \\
Griquas (Northern Cape) & 11400 & 0 & - \\
Griffons (North West) & 6275 & & \\
\hline
\end{tabular}

\section{Phase and level of play in which SCI occurred}

Of the SCIs $45 \%(N=126)$ occurred in the overall tackle phase, $28 \%$ of players sustaining an SCI while being tackled, consistent with previous reports; ${ }^{10-12} 37 \%$ occurred in the scrum; $60 \%(N=170)$ occurred at club level and $33 \%$ at school level; and $94 \%(N=171)$ occurred during match play, as previously found..$^{10}$ Sixteen per cent of players in this study considered that foul play had contributed to their injury, which is higher than previously reported in South Africa. ${ }^{10}$

\section{Playing position}

Forwards sustained $76 \%(N=139)$ of overall SCIs, with hookers accounting for $30 \%$ and flanks for $19 \%$ (Fig. 3). Twenty per cent of players with SCIs $(N=132)$ reported that they had not been playing in their normal position when injured.

Consistent with other studies, front-row players had the highest proportion of SCIs with hookers at greatest risk..$^{6,14-16}$ Hookers, who make up $6 \%$ of all players by number, ${ }^{6}$ sustained the highest number of SCIs, almost entirely owing to the increased risk during the set scrum. ${ }^{17}$ Flanks had the second highest number of SCIs. In contrast, in their study covering the period 1963 - 1989, Kew et al. ${ }^{12}$ found that flanks, scrumhalves and fullbacks were at least risk, sustaining only $5.6 \%$ of SCIs. This has changed substantially, possibly due to the increasing proportion of SCIs occurring during the tackling phase, especially when being tackled.

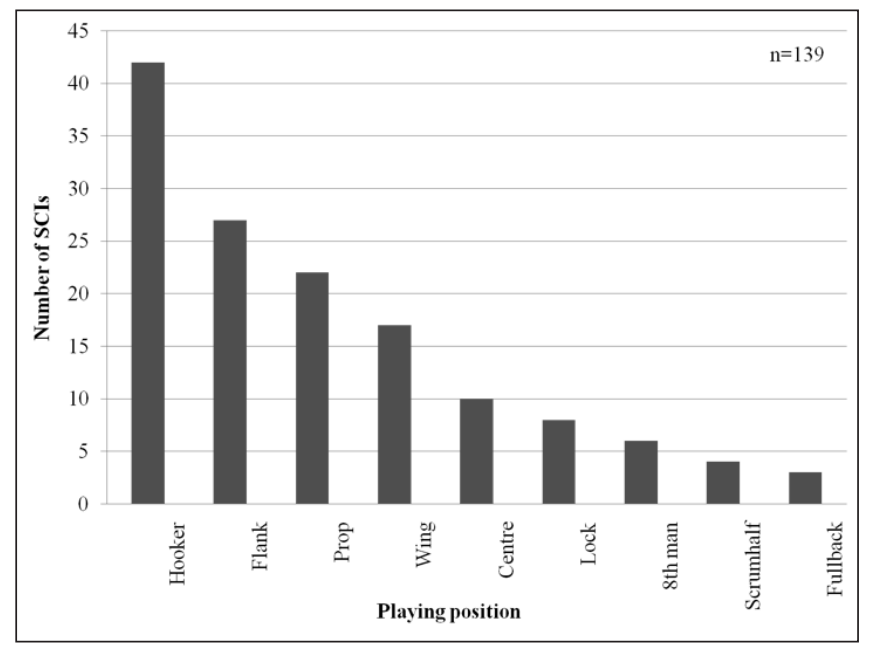

Fig. 3. Playing position and number of SCIs.

\section{Player demographics}

As socio-economic inequality is associated with health outcomes and ethnicity remains an important predictor of socio-economic status in SA, players were asked about their ethnicity. Of the SCI players $40 \%(N=183)$ were classified as white, $21 \%$ as black and $32 \%$ as mixed race/coloured. For $7 \%$ of players the classification was unknown. Of white players $56 \%$ recovered fully, compared with $34 \%$ of coloured and $10 \%$ of black players. This suggests either that white players enjoyed access to better medical resources under apartheid, and that these inequalities persist post-apartheid, or that more had medical insurance and therefore greater access to private health care. Black players had only a $50 \%$ chance of surviving an SCI. These data indicate an urgent need to prioritise preventive interventions and strategies to improve the acute management of SCIs among rugby players in previously disadvantaged communities. Table II provides further player demographics.

The median age of players with SCIs in this study was 21 years. The average age of players with SCIs in New Zealand was reported to be 22.8 years. ${ }^{6}$ Initially it was suggested that younger players were at greater risk of sustaining SCIs, but this was subsequently shown to be untrue. ${ }^{10,12}$ We found that the most common weight range for SCIs was $70-79 \mathrm{~kg}$. Quarrie et al..$^{18}$ reported that rugby union players with a body mass greater than $81 \mathrm{~kg}$ had a higher injury rate than players whose body mass was less than $74 \mathrm{~kg}$. The median height of players with SCI in this study was $179 \mathrm{~cm}$. Quarrie et al. ${ }^{18}$ also reported that rugby players whose heights ranged from 179 to $181 \mathrm{~cm}$ missed a greater proportion (16\%) of the rugby season due to injuries than shorter players. The absence of control data from uninjured players prevents conclusions regarding whether these reflect the most common heights and weights of rugby players or whether players at these heights and weights are at increased risk of injury.

Data on player experience suggest that those with more skill have more injuries, ${ }^{6,10}$ that greater forces are generated at higher levels of play, ${ }^{18}$ or that the risk of sustaining an SCI rises with greater exposure to rugby play. The link might be explained by the repetitive stress on skeletal and ligamentous systems, with premature and advanced degenerative changes of the cervical spine observed in rugby players, ${ }^{19}$ or that the greater forces generated by skilled or professional players increase the likelihood of injury. ${ }^{20}$ 


\section{Table II. Demographic and anthropometric data for players with SCI}

\begin{tabular}{|c|c|c|}
\hline & & $N^{*}$ \\
\hline Ethnicity and education & & 120 \\
\hline Players with tertiary education & $30 \%$ & \\
\hline White players with tertiary education & $81 \%$ & \\
\hline Black deceased players & $63 \%$ & 141 \\
\hline Deceased players who survived longer than 2 years after injury & $<50 \%$ & 21 \\
\hline \multicolumn{3}{|l|}{ Age } \\
\hline Median & 21 years & 165 \\
\hline Age with highest number of SCIs & 17 years & \\
\hline Injuries per age group (yrs) & & 151 \\
\hline $11-15$ & $5 \%$ & \\
\hline $16-18$ & $33 \%$ & \\
\hline $19-23$ & $27 \%$ & \\
\hline $24-30$ & $23 \%$ & \\
\hline $30+$ & $12 \%$ & \\
\hline Weight & & 108 \\
\hline Weight range & $38-115 \mathrm{~kg}$ & \\
\hline Weight average & $76.7 \mathrm{~kg}$ & \\
\hline Most common weight range & $70-79 \mathrm{~kg}$ & \\
\hline Height & & 101 \\
\hline Height range & $140-240 \mathrm{~cm}$ & \\
\hline Height median & $179 \mathrm{~cm}$ & \\
\hline Most common height range & $180-189 \mathrm{~cm}$ & \\
\hline Experience & & 115 \\
\hline Players older than 19 with more than 5 years of playing rugby & $85 \%$ & \\
\hline $\begin{array}{l}\text { Players with more than } 10 \text { years of playing rugby, irrespective of } \\
\text { playing position and phase of play }\end{array}$ & $43 \%$ & \\
\hline \multicolumn{3}{|l|}{ Conditioning } \\
\hline Players who did not participate in any pre-season conditioning sessions & $21 \%$ & 102 \\
\hline Players who participated in some form of conditioning sessions & $98 \%$ & 113 \\
\hline $\begin{array}{l}\text { Players (of } 98 \% \text { ) who participated in less than } 3 \text { pre-season } \\
\text { conditioning sessions per week }\end{array}$ & $50 \%$ & 103 \\
\hline $\begin{array}{l}\text { Players who participated in } 3 \text { or more conditioning sessions per } \\
\text { week during the season }\end{array}$ & $65 \%$ & 112 \\
\hline
\end{tabular}

Physical conditioning did not appear to reduce the risk of injury, since most injured players had undertaken some conditioning. Silver ${ }^{21}$ found that $18 \%$ of injuries to the spine occurred in players who were either unfit or had insufficient specific positional training. Paradoxically, Silver ${ }^{17}$ also considered that stronger and fitter players were at a greater risk of injury. The benefits of strength and fitness training for reducing (head and) neck injuries have not been formally addressed.

\section{The acute injury}

Of SCIs $55 \%$ were dislocations, $18 \%$ were fractures and $24 \%$ were fractures with dislocation ( $N=134) ; 38 \%$ occurred at the $\mathrm{C} 4 / \mathrm{C} 5$ and $31 \%$ at the $\mathrm{C} 5 / \mathrm{C} 6$ levels $(N=150)$. Previous studies have also indicated that most rugby-related SCIs occurred at these spinal levels. ${ }^{10-11,15}$ Compared with previous South African studies, ${ }^{10-11}$ the present results show increasing numbers of SCIs at the $\mathrm{C} 3 / \mathrm{C} 4$ and $\mathrm{C} 6 / \mathrm{C} 7$ spinal levels.

\section{On-field management}

The immediate management of injured players was generally inadequate (Table III). Medical personnel were present at only $50 \%$ of the games at which the SCI occurred, only $49 \%$ of injured players received appropriate spinal immobilisation on the playing field, $34 \%$ of injured players received no form of on-field management, and only $5 \%$ of injured players received optimal treatment - spinal immobilisation with body strapping to a rigid stretcher (spine board).

\section{Table III. On-field treatment}

\begin{tabular}{|c|c|c|}
\hline & $\%$ & $N^{*}$ \\
\hline Medical personnel in attendance at the field on the day of the incident & 50 & 109 \\
\hline Spinal immobilisation/alignment done on the field & 49 & 111 \\
\hline No form of on-field management & 34 & 111 \\
\hline $\begin{array}{l}\text { Managed correctly with a cervical collar, 'log-rolling', placed onto a spine } \\
\text { board with head blocks in place and the body strapped to avoid any movement }\end{array}$ & 5 & 111 \\
\hline
\end{tabular}


Seventy-five per cent of players $(N=118)$ were transported by ambulance to hospital, with $71 \%(N=130)$ being managed at public facilities. Of those treated at public facilities, $71 \%$ had catastrophic outcomes. Sixty-four per cent $(N=129)$ were taken to two or more medical facilities before definitive acute management of their SCI was initiated. Of players with catastrophic outcomes, $71 \%$ had been taken to two or more hospitals before definitive management was intiated. Fortynine per cent $(N=114)$ of players waited longer than 6 hours before their SCI was managed, with only $25 \%(N=114)$ being managed in less than 2 hours. Incorrect management of SCIs increases the probability of a catastrophic outcome. ${ }^{6}$

\section{Acute injury management: Impact of Spineline}

Spineline is a rapid response system to assist seriously injured rugby players anywhere in SA, aiming to provide proper spinal stabilisation and immediate transport to an appropriate trauma centre. Since its introduction in 2003 there have been 45 SCIs, only $27 \%$ of which were reported to Spineline.

\section{Outcomes}

Of players with an SCI, $61 \%(N=146)$ had a catastrophic outcome after 12 months, including $8 \%$ who died within a year after injury; $53 \%(N=112)$ spent longer than 5 months in hospital. Just over half of the 21 of the 69 deceased players for whom data were available died within 18 months of suffering the SCI. It is probable that SCI had a significant impact on life expectancy. We are not aware of any previous evaluation of survival time after a rugby-related SCI.

\section{Financial considerations}

No financial compensation was received by $66 \%(N=65)$ of players. Three players were willing to disclose their financial compensation; they had received between R150 000 and R200 000, between R100 000 and R120 000 and between R75 000 and R80 000, respectively. Of the players $29 \%(N=85)$ had medical aid or health insurance.

\section{Conclusion}

This study identified the following ongoing concerns: the absence of a compulsory comprehensive register for rugbyrelated SCIs in SA, uncertainty regarding the number of registered players, so that incident rates cannot be calculated for monitoring and future comparisons, and limited information on deceased players to calculate years of life lost. Such a register is essential to monitor the magnitude of the problem, identify potential risk factors, and formulate appropriate and timely interventions. It will facilitate the availability of reliable rugby-related SCI statistics, particularly in monitoring the neurological outcomes and survival data of previously disadvantaged players.

For further research, a standardised classification system for SCIs should be used to facilitate comparisons with local and international studies. As SA has limited resources, strengthening collaboration between provinces and between public and private health sectors in provinces without acute care facilities is likely to reduce the burden on the public sector. Utilisation of Spineline must improve, as it could alter the neurological outcomes of serious SCIs. Health insurance and appropriate compensation for this life-altering event require urgent attention. It is mostly previously disadvantaged players who carry the burden of poorly managed injuries, and legislation to guide proper financial compensation for players suffering catastrophic outcomes is urgently needed.

Ultimately, the strongest impact will be a preventive strategy. SA cannot undertake research such as that conducted by Quarrie et al.; quite apart from the cost, there are no structures for precise data collection. However, rugby administrators in SA have taken the lead by learning from the New Zealand Rugby Union and other rugby safety initiatives and have implemented BokSmart, a rugby safety programme under which Spineline is now placed.

South Africa is a developing country with limited resources, so sports injuries in this country may not be a government priority. Although rugby-related SCIs are uncommon, each burdens an already strained health care system and contributes to early life loss. Accurate, comprehensive and timely data are essential to define the magnitude of rugby-related SCIs, identify their contribution to SA's health burden and identify potential risk factors. This study is the first national attempt to record the number of rugby-related SCIs in SA and provide information that can be used to identify potential risk factors, including the role of socio-economic status.

Competing interests. The authors have no competing interests to declare.

References

1. Scher AT. Rugby injuries to the cervical spinal cord. S Afr Med J 1977; 51: 473.

2. Silver JR. Rugby injuries to the cervical spine cord. BMJ 1979; 1: 192-193.

. Williams JP, McKibbin B. Cervical spine injuries in rugby union football. BMJ 1978; 2: 1747.

4. Burry HC, Gowland H. Cervical injury in rugby football - a New Zealand survey. Br I Sports Med 1981; 15: 56-59.

5. Shelly MJ, Butler JS, Timlin M, Walsh MG, Poynton AR, O'Byrne JM. Spinal injuries in Irish rugby. A ten year review. Br J Bone Joint Surg 2006; 88: 771-775.

6. Quarrie KL, Cantu RC, Chalmers DJ. Rugby union injuries to the cervical spine and spinal cord. Sports Med 2002; 32: 633-653.

7 Haylen PT. Spinal injuries in rugby union, 1970-2003: Lessons and responsibilities. Med J Aus 2004; 181: 48-50.

8. Quarrie KL, Gianotti SM, Hopkins WG, Hume PA. Effect of nationwide injury prevention puarrie KL, Gianotti SM, Hopkins WG, Hume on serious spinal injuries in New Zealand rugby union: ecological study. BMJ
2007: 334: 1150-1160.

9. Noakes TD, Draper CE. Preventing spinal cord injuries. BMJ 2007; 334: 1122-1123.

10. Noakes TD, Jakoet I, Baalbergen E. An apparent reduction in the incidence and severity of spinal cord injuries in schoolboy rugby players in the Western Cape since 1990. S Afr Med J 1999; 9: 540-545.

11. Scher AT. Rugby injuries to the cervical spine and spinal cord: a ten year review. Clin Sports Med 1998; 17: 195-206.

12. Kew T, Noakes TD, Kettle AN, Goedeke RE, Newton DA, Scher AT. A retrospective study of spinal cord injury in Cape Province rugby players, 1963-1989: incidence, mechanisms and spinal cord injury in Cape Province rugby
prevention. $S$ Afr Med J 1991; 80: 123-133.

13. Scher AT. Catastrophic rugby injuries of the spinal cord: changing patterns of injury. $\mathrm{Br} \mathrm{J}$ Scher AT. Catastrophic rug $1991 ; 25: 57-60$
Sports

14. Armour KS, Clatworthy BJ, Bean AR, Wells JE, Clarke AM. Spinal injuries in New Zealand rugby and rugby league: a twenty-year survey. NZ Med J 1997; 110: 462-465.

15. Carmody DJ, Taylor TKF, Parker DA, Coolican MR, Cumming RG. Spinal cord injuries in Australian footballers 1997-2002. Med J Aust 2005; 182: 561-564.

16. Secin FP, Poggi EJ, Luzuriaga F, Laffaye HA. Disabling injuries of the cervical spine in Argentine rugby over the last 20 years. Br J Sports Med 1999; 33: 33-36.

7. Silver JR. Professionalism and injuries in rugby union. Br J Sports Med 2001; 35: 138 .

18. Quarrie KL, Alsop JC, Waller AE, Bird YN, Marshall SW, Chalmers DJ. The New Zealand rugby injury and performance project. VI. A prospective cohort study of risk factors for injury in rugby union football. $\mathrm{Br}$ J Sports Med 2001; 35: 157-166.

19. Scher AT. Premature onset of degenerative disease of the cervical spine in rugby players. $S$ Afr Med J 1990; 77: 557-558.

20. Silver JR. The impact of the 21st century on rugby injuries in rugby union. Spinal Cord 2002; 40: 552-559.

21. Silver JR. Injuries of the spine sustained in rugby. BMJ 1984; 288: 37-43. 